Proceedings

\title{
Reducing Energy Consumption and Carbon Footprint by Smart and Sustainable Use ${ }^{\dagger}$
}

\author{
Régis Decorme 1,*, Tracey Crosbie ${ }^{2}$, Vladimir Vukovic ${ }^{2}$, Mia Ala-Juusela ${ }^{3}$, Martin Klepal ${ }^{4}$, \\ Malcolm Yadack ${ }^{5}$, Martin Buchholz ${ }^{6}$ and Andrea Costa ${ }^{7}$ \\ 1 Centre Scientifique et Technique du Bâtiment (CSTB, Center for Science and Technology in Buildings), \\ 290 Route des Lucioles, 06904 Sophia Antipolis, France \\ 2 Technology Futures research institute, Campus Heart, Teesside University, Southfield Rd, \\ Middlesbrough TS1 3BX, UK; T.Crosbie@tees.ac.uk (T.C.); V.Vukovic@tees.ac.uk (V.V.) \\ 3 VTT Technical Research Centre of Finland Ltd., P.O. Box 1000, FI-02044 VTT, Finland; \\ Mia.Ala-Juusela@vtt.fi \\ 4 Cork Institute of Technology (CIT), Rossa Avenue, Bishopstown, T12 P928 Cork, Ireland; \\ Martin.Klepal@cit.ie \\ 5 Stuttgart Technology University of Applied Sciences, Schellingstraße 24, 70174 Stuttgart, Germany; \\ malcolm.yadack@uni-hohenheim.de \\ 6 Technische Universtiät Berlin (TU Berlin, Technical University of Berlin), Straße des 17. Juni 135, \\ 10623 Berlin, Germany; martin.buchholz@watergy.de \\ 7 R2M Solution S.r.l., Via Fratelli Cuzio, 42, 27100 Pavia, Italy; andrea.costa@r2msolution.com \\ * Correspondence: regis.decorme@cstb.fr; Tel.: +33-4-9395-6415 \\ † Presented at Sustainable Places 2017 (SP2017) Conference, Middlesbrough, UK, 28-30 June 2017. \\ Published: 11 December 2017
}

\begin{abstract}
The workshop "Reducing energy consumption and carbon footprint by smart and sustainable use" was organized on 29 June 2017 in the context of the International conference Sustainable Places 2017 with the aim to discuss the latest progress and innovations resulting from 7 projects developing solutions to reduce energy consumption and carbon footprint by smart and sustainable use.
\end{abstract}

Keywords: energy efficient buildings; demand response; energy storage; energy monitoring; district heating and cooling; smart grids; block of buildings

\section{Introduction}

This workshop was organized on 29 June 2017 in the context of the International conference Sustainable Places 2017 with the aim to discuss the latest progress and innovations resulting from 7 projects developing solutions to reduce energy consumption and carbon footprint by smart and sustainable use.

Participating projects (see Figure 1) were:

- $\quad$ DR-BOB-Demand Response in Block of Buildings (H2020)

- SIM4BLOCKS-Simulation Supported Real Time Energy Management in Building Blocks (H2020)

- STORY-Added value of STORage in distribution sYstems (H2020)

- inteGRIDy-Integrated Smart GRID Cross-Functional Solutions for Optimized Synergetic Energy Distribution, Utilization Storage Technologies

- H-DisNet-Intelligent Hybrid Thermo-Chemical District Networks (H2020)

- $\quad$ E2-DISTRICT - Energy Efficient Optimised District Heating and Cooling (H2020)

- INDIGO-Next generation, intelligent, high performance and affordable district cooling systems (H2020) 


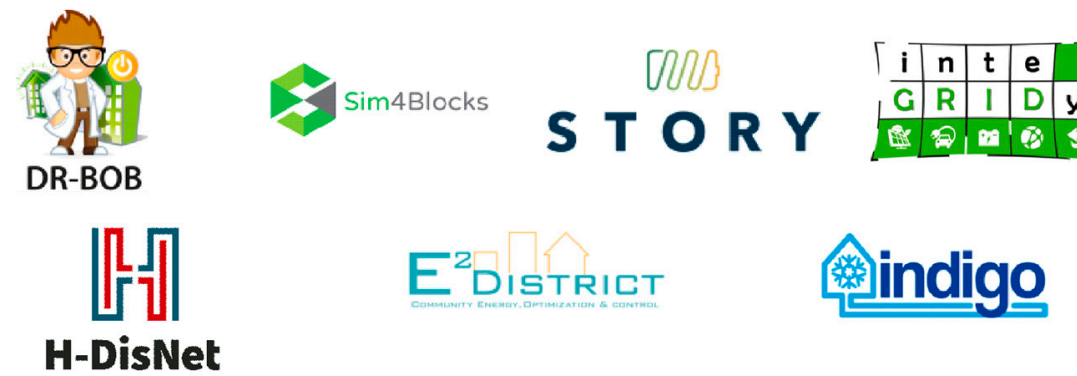

Figure 1. Logos of projects which participated to the workshop.

\section{Workshop Summary}

Innovation projects, funded by the European Commission, are conducting research into and/or the full-scale testing of more intelligent, efficient, affordable and socially acceptable energy management approaches for buildings, cites and districts. These projects are looking at the organisational and technical requirements in both new and existing buildings. Some are aiming for near zero emissions, some near zero energy, and some are aiming for energy positive buildings and/or places. They include work focusing on retrofitting buildings, renewable heating and cooling, highly efficient industries and mass take-up of energy efficient solutions and services by local government, businesses, individuals and communities.

Each project presented itself (see Figure 2) to the others with a 10' presentation covering:

1. A reminder of the project objectives and an update on the latest project progress (5')

2. A focus on ONE specific aspect/innovation/task of the project to be shared with sister projects and potentially leading to synergistic R\&D and collaboration between our projects $\left(5^{\prime}\right)$


Figure 2. Pictures from the workshop.

\section{Project Descriptions and Cooperation Offers}

Cooperation offers which have been presented are summarized in the table below-Discussion was initiated during the workshop and should continue offline.

\subsection{DR-BoB Project}

DR-BoB (http://www.dr-bob.eu/) aims to demonstrate the economic and environmental benefits of demand response in blocks of buildings for the actors required to bring it to market.

DR-BoB develops a method of assessing and validating the technology readiness of building stock to participate in the DR-BoB energy management solution at any given site. This DRTRLDemand Response Technology Readiness level-definition was presented at the workshop; sister projects are invited to provide feedback on DRTRL levels \& requirements and potentially use this DRTRL in the context of their project. 


\subsection{SIM4BLOCKS Project}

SIM4BLOCKS (http://www.sim4blocks.eu) stands for "Simulation Supported Real Time Energy Management in Building Blocks". The project develops innovative demand response services for residential and commercial applications. It combines decentralised energy management technology at the blocks-of-buildings-scale to enable Demand Response.

SIM4BLOCKS has highlighted the 3 followings areas where a potential cooperation with sister projects would be appreciated:

- DR-BOB

- Synergies in the monitoring phases for Demand Response projects

- Necessary data protection considerations.

- Uniform data collection and comparable (and combinable) data

\subsection{STORY}

STORY (http://horizon2020-story.eu/) aims to (1) demonstrate and evaluate innovative approaches for energy storage systems; (2) find solutions, which are affordable, secure and ensure an increased percentage of self-supply of electricity and (3) accelerate innovation and business models for deployment of storage at local level.

STORY presented the BRIDGE initiative: This Coordination and support Action is a collaboration instrument for "LCE 6 to 10" projects. It is composed of 4 working groups around the following topics:

- Business Models

- Consumer Engagement

- Data Management

- Regulation

Sister projects are welcome to follow and contribute to the discussion when relevant for their project.

\section{4. inteGRIDy}

inteGRIDy (http://www.integridy.eu/) focuses on the demonstration of smart grid, storage and system integration technologies with increasing share of renewables. inteGRIDy introduced the following cooperation areas:

- Platform for hosting interoperable solutions

- APIs to enable interoperability

- Joint dissemination/exploitation

- Collaboration with related LCE and other projects (see above BRIDGE initative)

\subsection{H-DisNet Project}

H-DisNet (http://www.h-disnet.eu/) contributes to next-generation of district energy networks developing the innovative thermo-chemical (TC) network technology. The technology exploits the high chemical potential of absorption processes for loss-free transport and storage of energy potential.

H-DisNet chose to share the following lessons learnt, relevant for sister projects also targeting optimization of District Energy networks:

- Low temperature heat for TCF regeneration can be used from heat network return-Connection of TC micro networks to conventional network, can be alternative to multi temperature network

- Heating in combination with heat pump and demand side thermal storage allows new constellations for smart grid integration

- TC Networks can be installed in addition to electric- or gas network, can be solution for remote urbanised areas, until now not suitable for heat networks 


\subsection{E2DISTRICT Project}

E2DISTRICT (http://e2district.eu/) develops (1) a District Management and Decision Support framework and (2) End-User Behaviour Demand Response (BDR) Strategies to manage Smart Energy Usage for sustainable District Heating and Cooling systems, targeting energy savings of up to $30 \%$.

An important area of research of E2DISTRICT relates to Demand-side behavior analysis. Collaboration with sister projects is appreciated on methods and tools for appropriate people engagement, incentives and rewarding methods and tools.

\subsection{INDIGO Project}

INDIGO (http://www.indigo-project.eu/) focuses on the development of a more efficient, intelligent, and cheaper generation of DC systems by improving system planning, control, and management.

INDIGO shared the following questions with sister projects and is willing to further discuss them after the workshop:

- Are there tools developed for DHC network planning?

- Is anybody using Modelica and willing to share models in the open library format?

- INDIGO shared the following questions with sister projects and is willing to further discuss them after the work.

INDIGO suggested to re-organize this round table next year at SP2018, and explained the current main challenges it is facing at the moment:

- To deploy installations of sensors actuator

- To validate our demand models

- To develop the controllers

Acknowledgments: The involved projects were co-funded by the European Union under the H2020 programme.

Author Contributions: Paper written by Regis Decorme and reviewed by all co-authors.

Conflicts of Interest: The authors declare no conflict of interest.

Appendix A. Workshop Agenda

\begin{tabular}{|c|c|c|}
\hline 08:30 & Workshop introduction & Régis Decorme-CSTB \\
\hline \multicolumn{3}{|c|}{ Demand-Response in block of buildings } \\
\hline & DR-BOB & Tracey Crosbie-Teesside University \\
\hline & SIM4BLOCKS & Malcolm Yadack-Stuttgart University of Applied Sciences \\
\hline \multicolumn{3}{|c|}{ Smart grids and storage } \\
\hline & Story & Mia Ala-Juusela-VTT \\
\hline & inteGRIDy & Vladimir Vukovic-Teesside University \\
\hline \multicolumn{3}{|c|}{ Technology for district heating and cooling } \\
\hline & H-DisNet & Martin Buchholz-Technische Universtiät Berlin \\
\hline & E2-District & Martin Klepal-CIT \\
\hline & INDIGO & Andrea Costa-R2M Solution \\
\hline 10:00 & End of the workshop & \\
\hline
\end{tabular}




\section{Appendix B. Workshop Pictures}

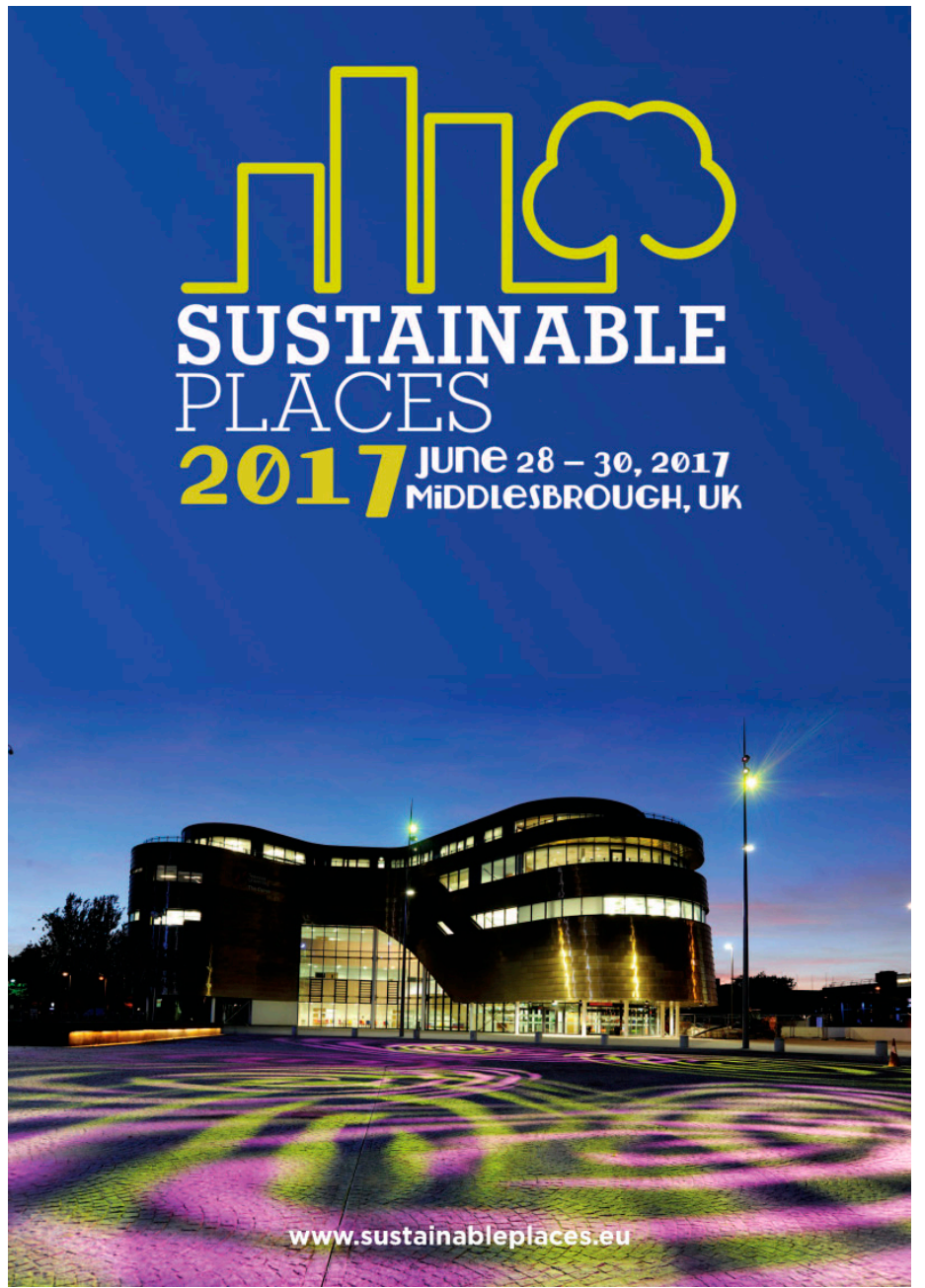

(C) 2017 by the authors. Licensee MDPI, Basel, Switzerland. This article is an open access article distributed under the terms and conditions of the Creative Commons Attribution (CC BY) license (http://creativecommons.org/licenses/by/4.0/). 